\title{
Relationship of Psychomotor Abilities in Relation to Selected Sports Skill in Volleyball
}

\author{
Bhupinder Singh ${ }^{1}$, Jagdeep Singh ${ }^{2}$ \\ ${ }^{1}$ Shaheed Kanshi Ram College of Physical Education, Kharar, Punjab, India \\ ${ }^{2}$ Department of Physical Education, Guru Nanak Dev University, Amritsar, Punjab, India
}

Email address:

jagdeep_majra@yahoo.co.in (J. Singh)

\section{To cite this article:}

Bhupinder Singh, Jagdeep Singh. Relationship of Psychomotor Abilities in Relation to Selected Sports Skill in Volleyball. Science Journal of Education. Vol. 4, No. 2, 2016, pp. 27-31. doi: 10.11648/j.sjedu.20160402.12

Received: April 26, 2015; Accepted: February 10, 2016; Published: March 16, 2016

\begin{abstract}
The aim of the study is to assess the relationship psychomotor abilities in relation to selected sports skill in volleyball. A group of One Hundred Twenty $(\mathrm{N}=120)$ male Inter University Level Volleyball Players of northern region of India were selected purposively to attain the objectives of the study. All the subjects, after having been informed about the objective and protocol of the study, gave their consent and volunteered to participate in this study. Online Pearson Correlation Coefficient Calculator used in data analysis. The Pearson's product moment correlation coefficient method used to find out the relationship between selected psychomotor abilities, coordinative abilities and skill related components of fitness with selected sports skill in volleyball. The level of $\mathrm{p} \leq 0.05$ was considered significant. Summarizing from the above findings we can say that the psychomotor abilities (i.e., Kinesthetic Perception and Speed of Movement) significantly influence the performance of Serve, setting and reception in volleyball players.
\end{abstract}

Keywords: Psychomotor Abilities, Volleyball Players, Skills

\section{Introduction}

Volleyball is the most popular sport in the world. People of all ages and skill levels play volleyball in over 200 countries around the world. Volleyball is a fast game that changes constantly, to be a successful athlete requires the ability to assess situations as they happen and having the skills to adjust. The increased competitiveness in sport demands that players achieve their optimum performance levels in a methodical manner with clearly defined performance objectives and training programs. The ability of volleyball players' to use behavioral and psychological routines can positively affect their performance (Voight 2005). The developing tendencies in international sports, especially in team games are identified as the increase in game tempo, tougher body game and greater variability in technique and tactics. An increased performance level can only be achieved by working and training of all major components i.e. technique, coordination, tactics, physical fitness, physiological and psychological qualities. This has motivated sports administrators, coaches, managers and players to spend time and resources evaluating their sports more scientifically. This requires that certain objective parameters be used to determine current performance and to monitor changes in performance. These parameters include anthropometric characteristics, physiological variables and sports specific skills. Therefore, it is important to understand that what may be optimal in terms of mechanical technique may be suicide in terms of real-life game-situation tactics. Expressed differently, mechanically optimal and tactically optimal. Biomechanics is often applied to volleyball to define the characteristics of skills, to gain an understanding of their mechanical effectiveness and to identify factors essential for optimal performance. There has been a considerable amount of biomechanical literature concerning the volleyball sport, both in training (Samson \& Roy, 1975 Oka et al. 1975) and competitive matches (Coleman, 1993 \& Katsikadelli 1996). Psychomotor abilities are skills such as hand-eye coordination, balance, and reaction time that arise from a unity of cognitive and physical functions. Psychomotor Abilities is a perceptual- motor skill that involves the integrationand processing of visual information in the central nervous system so that purposeful motor movements can be 
made (Abernethy B 1987). Psychomotor skills can be defined as merely muscular actions modified by learning variables. Psycho-motor tasks are elaborately interpreted to these situations that require the identification and combination of stimulus organism response elements in the coordinated spatio-temporal patterns of receptor effectors activity as a joint function of practice, repetition and reinforcing feedback so as to optimize probability, amplitude and time score in their acquisition, retention and transformation (Noble 1968). All healthy people develop some psychomotor abilities during the course of early development, and many people choose to develop those abilities further for work, athletics, or other activities. A baseball player, for instance, needs to develop his hand-eye coordination and reaction time more so than a normal person in order to consistently hit the ball. Psychomotor learning is the process by which individuals build the cognitive and physical connections necessary to gain such abilities. Over time, as one practices such abilities, the cognitive aspect becomes less and less important, as the action itself becomes automatic.

\section{Material and Methods}

\subsection{Selection of Subjects}

A group of One Hundred Twenty $(\mathrm{N}=120)$ male Inter University Level Volleyball Players of northern region of India were selected purposively to attain the objectives of the study. All the subjects, after having been informed about the objective and protocol of the study, gave their consent and volunteered to participate in this study. The details of the subjects are presented in table-1.

Table 1. Details of Subjects.

\begin{tabular}{lll}
\hline Sr. No. & Name of University & Subjects \\
\hline 1. & Guru Nanak Dev University, Amritsar. & 12 \\
2. & Panjab University, Chandigarh & 12 \\
3. & Himachal University, Shimla. & 12 \\
4. & Kurukshetra University, Kurkshetra. & 12 \\
5. & Lovely Professional University, Phagwara. & 12 \\
6. & Maharshi Dayanand University, Rohtak & 12 \\
7. & Chaudhary Charan Singh University, Meerut & 12 \\
8. & Delhi University, Delhi. & 12 \\
9. & Chaudhary Devi Lal University, Sirsa. & 12 \\
10. & Amity University, Noida. & 12 \\
Total & & $(\mathrm{N}=120)$ \\
\hline
\end{tabular}

Table 2. Details of Psychomotor Abilities.

\begin{tabular}{|c|c|c|c|}
\hline Sr. No & Variables & Tools of Measurement & Unit of Measurement \\
\hline 1. & $\begin{array}{l}\text { Kinaesthetic } \\
\text { Perception }\end{array}$ & Horizontal Space Test & Centimetres \\
\hline 2. & $\begin{array}{l}\text { Speed of } \\
\text { Movement }\end{array}$ & $\begin{array}{l}\text { Nelson Speed of } \\
\text { Movement Test }\end{array}$ & Seconds \\
\hline
\end{tabular}

Table 3. Details of Selected Sports Skill in Volleyball.

\begin{tabular}{llll}
\hline Sr. No & Skills & Tools of Measurement & Unit of Measurement \\
\hline 1. & Service & Serve Test & Score in points \\
2. & Setting & Set Test & Score in points \\
3. & Reception & Forearm Pass Test & Score in points \\
\hline
\end{tabular}

\subsection{Selection of Variables}

A feasibility analysis as to which of the variables could be taken up for the investigation, keeping in view the availability of equipment, acceptability to the subjects and the legitimate time that could be devoted for tests and to keep the entire study unitary and integrated was made in consultation with experts. With the above criteria's in mind, the following were variables selected for the present investigation.

\subsection{Administration of Tests and Collection of Data}

\section{Kinesthetic Perception}

Purpose: to measure the kinesthetic perception of the subject.

Procedure: A yardstick was placed on the wall approximately at eye level, while student was in sitting position. The subject was asked to sit on the chair facing the yardstick and after having seen and memorized its position. Then subject was blind folded and without a practice trial he pointed the index finger of his right hand to the point indicated by instructor.

Scoring: The score was the deviation from the desired mark, measured to nearest quarter inch. The final score was the total of the deviation on three trials.

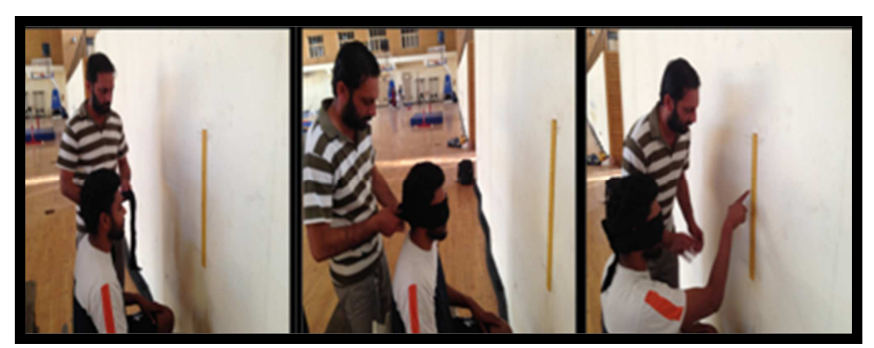

Figure 1. Subject Performing Horizontal Space Test.

Speed of Movement

Purpose: To measure combined reaction and speed of movement of the hands and the arms.

Procedure: The subject set on a chair with his hands resting on the edge of the table at marked lines $30 \mathrm{~cm}$ apart, palms facing each other. The tester held the time i.e. wooden meter scale near its top and it hung right midway between the subject's palms and the timer scale positioned evenly with the upper edges of the subjects index fingers. After the preparatory command 'ready' was given, the timer scale was dropped and the subject attempted with a horizontal movement and stopped it as quickly as possible by clapping the hands together. Twenty trails were given to every one of the subjects.

Scoring: The score for the combined response movement read from the timer/scale at the point just above the upper edge of the hand after the catch was made. The five slowest and five fastest trails were discarded and an average of the middle ten trails were recorded as the subjects score. This distance was then computed to time score by the following formula: 


$$
\text { Time }=\frac{\sqrt{2} \times \text { Distance the timer } / \text { scale falls }}{\text { Acceleration due to gravity }}
$$

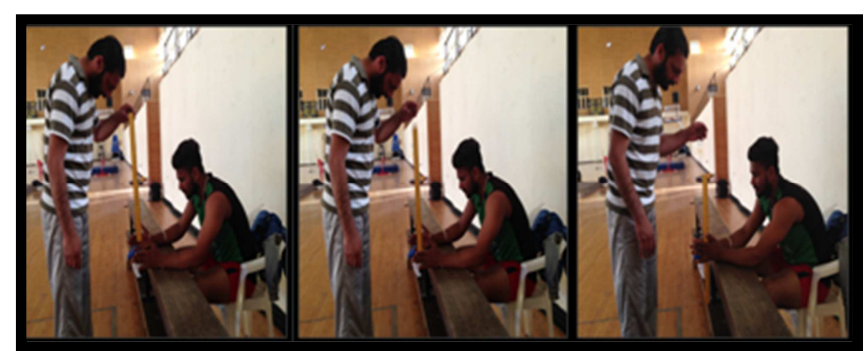

Figure 2. Subject Performing Speed of Movement.

Serve Test

Purpose: This test is conducted to test the skill in the volleyball serve consistency and accuracy.

Procedure: The examinee subject was asked to make skilled volleyballs for 10 times. He may use either 10 overhand or 10 underhand serves at one's preference. The examinee was told to avail 10 attempts of performing the skilled services only from the service area.

Scoring: Points were awarded for each of the 10 serves as per points assigned to various areas. Balls landing touching any line are awarded the higher point to the best advantage of the examinee. Thus, the maximum score which a best skilled person can obtain is 40 i.e. when all the 10 serves land in narrow back area marked for 4 points each. All the balls landing outside the point's award areas were given zero points.

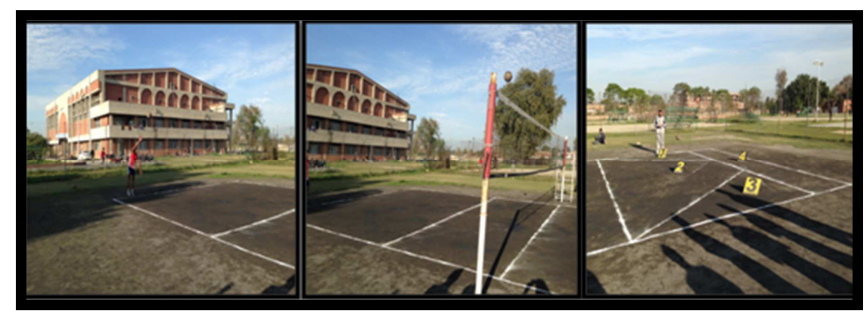

Figure 3. Subject Performing Serve Test.

\section{Set Test}

Purpose: The purpose of this test item is to measure the consistency, accuracy and height setting of the volleyball.

Procedure: The tester assumed the position near the centre of the court, 10 feet in front of the back line. The subject was positioned at a point shown by $\mathrm{X}$ i.e. 6 feet from the right side line and five feet back from the net. The tester tosses a ball to the subject. The subject was instructed to set the tossed ball over the 10 feet high string in such a way so as to score maximum marks as indicated by point values indicated in Fig. 4. After the first demonstration round, the tosser gives 10 correct tosses of the ball to the examinee while the examinee makes best efforts to score maximum by setting the ball height accurately with an attempt to score maximum points.

Scoring: Points were awarded to each ball set as per the value of the target touched by the respective ball. The scoring area was divided into six rectangular zones. The first rectangle is $2^{\prime} \times 1^{\prime}$ 'with its longer axis parallel to central line of the court. The rest of the rectangles were perpendicular in their length to the length of the 11' long rectangle. Four rectangles were 2' x 7' 10 " while the last rectangle towards left side line is $3^{\prime} \times 7^{\prime} 10^{\prime \prime}$. The points awarded to each rectangles were indicated in Fig. 4. A total score was calculated by summing up the individual scores of 10 correct tossed given by the tosser to the subject. Zero point was to be awarded if any ball touched the ground outside the scoring area or went under the string and for those balls as hit the net.

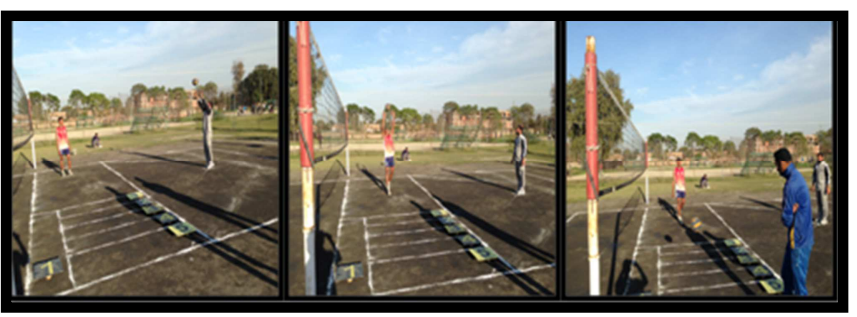

Figure 4. Subject Performing Set Test.

\section{Reception Test}

Purpose: This item measures one's skill ability of Reception.

Procedure: The tester tossed the ball over the net to the intended pass receiving area by making a two-handed overhead toss. Particular attention was given by the tester that all the tosses are good. The poor toss, if any must be repeated. The examinee was asked to use a forearm pass to send the ball over the 8-feet string into the desired best scoring target areas as shown in figure 5.

Scoring: A maximum of 50 points were possible. However, the actual points were recorded as per the fall of the ball in the target areas. Each target area had been encircled marks shown in Fig.5 in their respective rectangular target areas marked. Any ball not reaching any target area was given zero point. However, in case the ball was on a line dividing the target areas, the higher scoring is given to the subject.

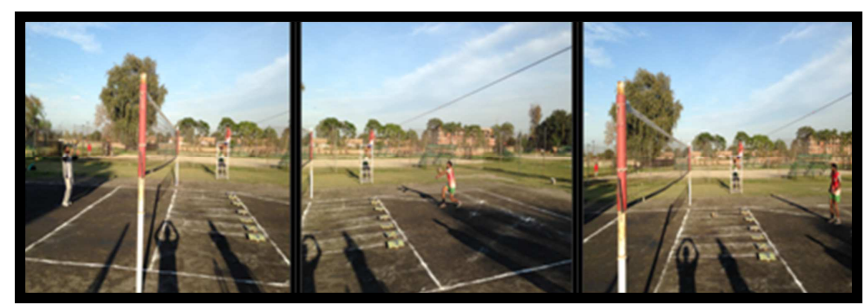

Figure 5. Subject Performing Fore-Arm Pass Test.

\section{Statistical Analysis}

Online Pearson Correlation Coefficient Calculator used in data analysis. The Pearson's product moment correlation coefficient method used to find out the relationship between selected psychomotor abilities, coordinative abilities and skill related components of fitness with selected sports skill in volleyball. The level of $\mathrm{p} \leq 0.05$ was considered significant. 


\section{Results}

An examination of table- 4 indicates that serve skill was significantly related to psycho motor abilities variables i.e., Kinesthetic Perception ( $\mathrm{r}=-0.17223)$ and Speed of Movement $(\mathrm{r}=-0.1632)$ as obtained value of correlation coefficient of these variables were greater than the tabulated value 0.195 required for the correlation to be statistically significant at 0.05 level of confidence. The graphical representation of relationship between both the groups has been presented graphically in figure-6.

Table 4. Relationship of Psycho Motor Abilities (i.e., Kinesthetic Perception and Speed of Movement) with the Performance of Volleyball Player in Serve.

\begin{tabular}{lll}
\hline Sr. No. & Variables & Coefficient of Correlation (r) \\
\hline 1 & Kinesthetic Perception & -0.17223 \\
2 & Speed of Movement & -0.1632 \\
\hline
\end{tabular}

*Significant at.05 level of significance $\mathrm{r}_{.05}(118)=0.195$

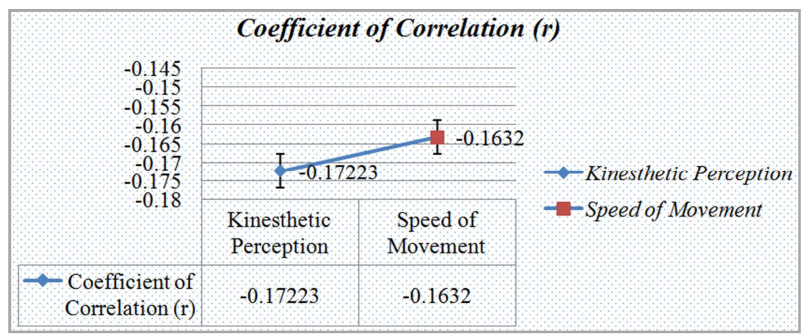

Figure 6. Relationship of Psycho Motor Abilities (i.e., Kinesthetic Perception and Speed of Movement) with the Performance of Volleyball Player in Serve.

Table 5. Relationship of Psycho Motor Abilities (i.e., Kinesthetic Perception and Speed of Movement) with the Performance of Volleyball Player in Setting.

\begin{tabular}{lll}
\hline Sr. No. & Variables & Coefficient of Correlation (r) \\
\hline 1 & Kinesthetic Perception & -0.1252 \\
2 & Speed of Movement & -0.04 \\
\hline
\end{tabular}

*Significant at.05 level of significance $\mathrm{r}_{.05}(118)=0.195$

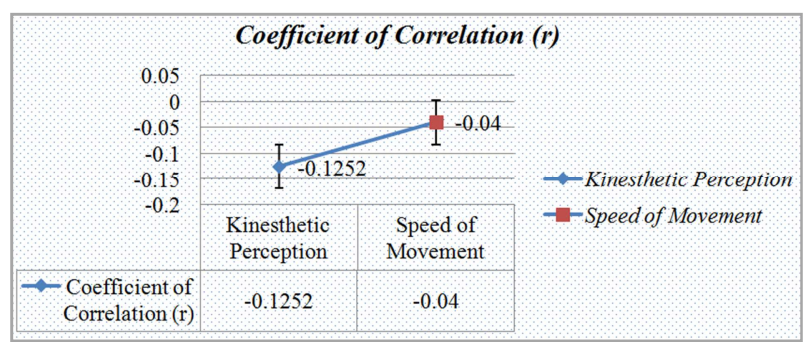

Figure 7. Relationship of Psycho Motor Abilities (i.e., Kinesthetic Perception and Speed of Movement) with the Performance of Volleyball Player in Setting.

An examination of table-5 indicates that setting skill was significantly related to psycho motor abilities variables i.e., Kinesthetic Perception ( $\mathrm{r}=-0.1252)$ and Speed of Movement $(\mathrm{r}=-0.04)$ as obtained value of correlation coefficient of these variables were greater than the tabulated value 0.195 required for the correlation to be statistically significant at 0.05 level of confidence. The graphical representation of relationship between both the groups has been presented graphically in figure-7.

Table 6. Relationship of Psycho Motor Abilities (i.e., Kinesthetic Perception and Speed of Movement) with the Performance of Volleyball Player in Reception.

\begin{tabular}{lll}
\hline Sr. No. & Variables & Coefficient of Correlation (r) \\
\hline 1 & Kinesthetic Perception & -0.1278 \\
2 & Speed of Movement & -0.2686 \\
\hline
\end{tabular}

*Significant at.05 level of significance $r_{.05}(118)=0.195$

An examination of table-6 indicates that reception skill was significantly related to psycho motor abilities variables i.e., Kinesthetic Perception $(\mathrm{r}=-0.1278)$ and Speed of Movement $(\mathrm{r}=-0.2686)$ as obtained value of correlation coefficient of these variables were greater than the tabulated value 0.195 required for the correlation to be statistically significant at 0.05 level of confidence. The graphical representation of relationship between both the groups has been presented graphically in figure- 8 .

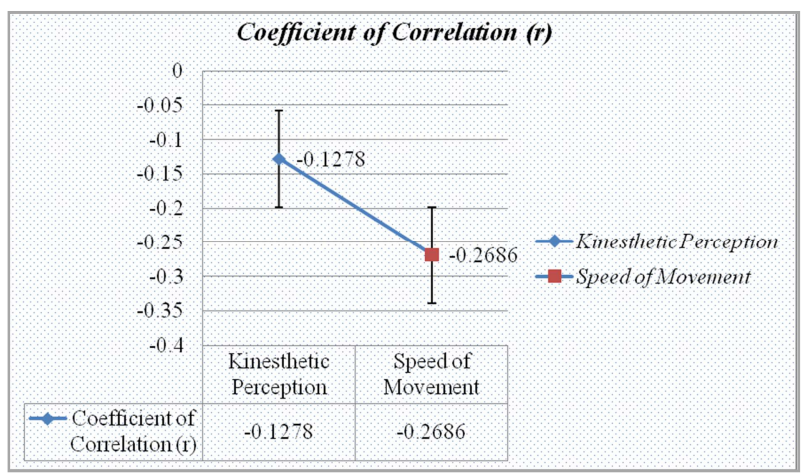

Figure 8. Relationship of Psycho Motor Abilities (i.e., Kinesthetic Perception and Speed of Movement) with the Performance of Volleyball Player in Reception.

\section{Conclusions}

Summarizing from the above findings we can say that the psycho motor abilities (i.e., Kinesthetic Perception and Speed of Movement) significantly influence the performance of Serve, setting and reception in volleyball players.

\section{Acknowledgements}

Authors would like to thank department of Physical Education and Sports (AT) Guru Nanak Dev University, Amritsar (Punjab) for providing assistance in collecting the relevant information for undertaking quality research.

\section{References}

[1] Samson J, Roy B (1975). Biomechanical analysis of the volleyball spike. In Biomechanics V-B (edited by P. Komi) Baltimore: Baltimore University Press, pp. 332-336. 
[2] Oka H, Okamoto T, Kumamoto M (1975). Electromyographic and cinematographic study of the volleyball spike. In Biomechanics V-B (edited by P. Komi), Baltimore: Baltimore University Press, pp. 326-331.

[3] Voight, M. (2005). Mental toughness training for volleyball: Maximizing technical \& mental mechanics. Monterey, CA: Coaches Choice Books.

[4] Coleman SGS, Benham AS, Northcott SR (1993). A threedimensional cinematographically analyses of the volleyball spike, Journal of Sports Sciences, 11: 295-302.

[5] Nobel, CE (1968). The learning of psychomotor skills. Annual Review of Psychology, 19: pp. 203-250.

[6] Katsikadelli A (1996). Comparative studies of the attack serve in high-level volleyball tournaments, Journal of Human Movement Studies, 30: 259-267.
[7] Kansal DK (1996). Applied Measurement, Evaluation \& Sports Selection. (2nd ed.) Sports \& Spiritual Science Publications, pp. 377-379.

[8] Abernethy B (1987). Review: Selective Attention in Fast Ball Sports II: Expert-Novice Differences. Australian Journal of Science and Medicine in Sport, 19 (4) 7-16.

[9] Barry LJ, Nelson JK (1988). Practical Measurements for Evaluation in Physical Education (3rd ed.), Surjeet Publication, pp. 245-246.

[10] Barry LJ, Nelson JK (1988). Practical Measurements for Evaluation in Physical Education (3rd ed.), Surjeet Publication, pp. 248-249. 